\title{
A new curriculum for fiber-optic systems
}

\section{Bruce Ferguson}

Bruce A. Ferguson, "A new curriculum for fiber-optic systems," Proc. SPIE 9663, Eighth International Topical Meeting on Education and Training in Optics and Photonics, 96630Y (6 October 2003); doi: 10.1117/12.2208456

SPIE Event: Eighth International Topical Meeting on Education and Training in Optics and Photonics, 2003, Tucson, Arizona, United States 


\title{
A new curriculum for fiber-optic systems
}

\author{
Bruce A. Ferguson \\ Rose-Hulman Institute of Technology, 5500 Wabash Avenue, Terre Haute, IN 47803-3999 \\ telephone: 812877 8340; fax: 812877 8895; e-mail:ferguson@rose-hulman.edu
}

\begin{abstract}
A new approach to senior-level fiber optics and photonics curricula is presented. The approach shifts the education goals' focus from device construction and physics to system level integration and performance. A revised curriculum is presented, and feedback from students in the initial offering is provided.

(C2003 Optical Society of America
\end{abstract}

OCIS codes: (000.2060) Education; (060.2360) Fiber optics links and subsystems

Fiber optic and photonic technology is now commonplace in the professional worlds of communications, sensing, and networking. For many years, electrical engineering programs have offered senior-level fiber optics technical electives introducing students to this technology. As the technology has matured, and applications have become both more elaborate and demanding, the need for students familiar with the special considerations of engineering these systems has grown. However, the form of the educational offerings most often provided has not changed to help better prepare students for work in the field.

A new curriculum has been developed to accommodate the shift in fiber optic engineering emphasis from devices to system level design and performance. This approach encourages students to learn the details by presenting first the system architectures, system performance measures, and system engineering issues. Device operation and theory are included, but are not the main approach to studying fiber optics. In this fashion, device operation and theory are left for a subsequent course.

A senior level course has been offered using this approach. Initial student feedback is positive, and the students are able to perform at system level problems.

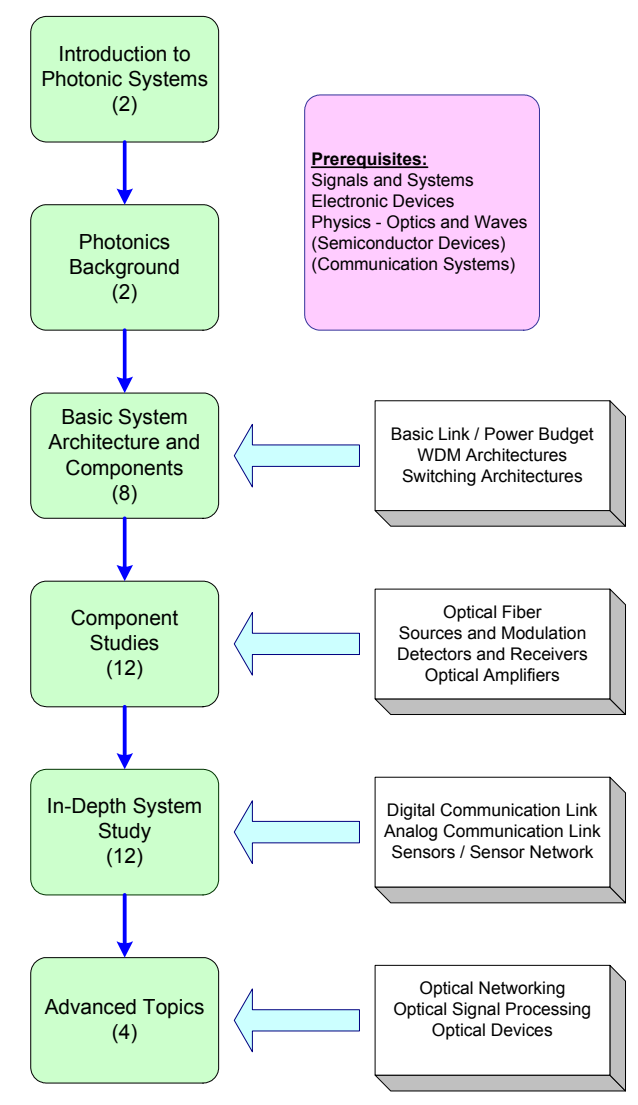

Fig. 1. Fiber optics curriculum flow for 40 class term.

Eighth International Topical Meeting on Education and Training in Optics and Photonics,

edited by Barry L. Shoop, Grover Swartzlander Jr., Proc. of SPIE Vol. 9663, 96630Y

(C) 2003 SPIE, OSA, ICO · doi: 10.1117/12.2208456

Proc. of SPIE Vol. 9663 96630Y-1 